Retrospective Assessment

\title{
e What Is the Prevalence of Symptomatic Obstructive Sleep Apnea Syndrome in Chronic Spinal Pain Patients? An Assessment of the Correlation of OSAS with Chronic Opioid Therapy, Obesity, and Smoking
}

\author{
Sanjana Pampati, BS, BA ${ }^{1}$, and Laxmaiah Manchikanti, MD²
}

From: ${ }^{1}$ University of Michigan School of Public Health, Ann Arbor, MI; ${ }^{2}$ Pain Management Center of Paducah, Paducah, KY, and University of Louisville, Louisville, KY

Sanjana Pampati is a first year student M.P.H. Epidemiology Methods and Applications at the

University of Michigan School of Public Health. She is working as a research assistant at the

Center for Social Epidemiology and Population Health, Ann Arbor, MI, and School of

Nursing, Ann Arbor, MI. Dr. Manchikanti is Medical Director of the Pain Management Center of Paducah, Paducah, KY, and Clinical Professor, Anesthesiology and Perioperative Medicine, University of Louisville, Louisville, KY.

Address Correspondence: Sanjana Pampati, BS, BA University of Michigan School of Public Health

1415 Washington Heights Ann Arbor, MI 48109-2029

E-mail:

sanjana.pampati@gmail.com

Disclaimer: There was no external funding in the preparation of this manuscript.

Conflict of interest: Dr.

Manchikanti has provided limited consulting services

to Semnur Pharmaceuticals, Incorporated, which is developing nonparticulate steroids.

Manuscript received: Revised manuscript received: Accepted for publication:

Free full manuscript: www.painphysicianjournal.com
Background: In modern medicine, obstructive sleep apnea syndrome (OSAS) is a commonly described sleep disorder with airway obstruction, disrupted sleep, and excessive daytime sleepiness. Since its description in 1976 by Guilleminault et al, numerous epidemiologic studies and systematic reviews, with multiple comorbidities related to cardiovascular sequelae, altered cognitive function, and multiple other potential complications have been described. Multiple risk factors have been identified included obesity, smoking, alcohol consumption, and other factors. Chronic pain and chronic opioid therapy also have been described to contribute to a large proportion of patients with OSAS. Chronic pain, obesity, smoking, and chronic opioid therapy are often found together, yet there is a paucity of literature describing OSAS in chronic pain patients.

Objectives: To assess the prevalence of symptomatic OSAS in chronic spinal pain patients receiving chronic opioid therapy and determine the association of OSAS with multiple risk factors and comorbidities.

Study Design: A retrospective assessment of patients who attend a single interventional pain management practice from January 1, 2010to December 31, 2014.

Setting: A private interventional pain management practice in the United States.

Methods: The data were collected from 4,036 consecutive patients presenting for assessment to a pain management center from January 1, 2010 to December 31, 2014. All assessments were comprehensive and performed by 2 physicians. The comprehensive assessment included a complete history, a physical examination, and a review of records.

Results: The prevalence of OSAS in patients with chronic spinal pain was $13.8 \%$. The results showed a higher prevalence in males compared to females (15.1\% versus $12.8 \%)$, a higher prevalence in those aged 45 or older compared to those $25-45$ years and those $18-25$ years ( $16.3 \%$ versus $10.7 \%$ or $2.5 \%$ ), higher prevalence in Hispanics and Asians compared to African Americans and whites $(23.7 \%$ versus $16.2 \%$ versus $13.4 \%$ ), higher prevalence in patients with combined back and neck pain compared to patients with thoracic pain only or back pain only (16.3\% versus $8.2 \%$ to $11 \%)$. Prevalence also varied by body mass index (BMI): $32.4 \%$ in morbidly obese patients, $20.3 \%$ in severely obese patients, $15.7 \%$ in obese patients, $9.2 \%$ in those who were overweight, and only $5.7 \%$ in those with normal weight. A significant correlation with OSAS was also observed in patients smoking more than 40 pack years and multiple respiratory symptoms except for chronic bronchitis and multiple cardiovascular ailments.

Limitations: The retrospective nature of the assessment.

Conclusion: This retrospective assessment of over 4,000 patients suffering from chronic pain and receiving chronic opioid therapy indicated a prevalence of sleep apnea syndrome as $13.8 \%$. Multiple risk factors including obesity, chronic obstructive pulmonary disease (COPD), chronic sinus and nasal discharge, and multiple comorbidities including cardiovascular and related ailments have been identified.

Key words: Obstructive sleep apnea syndrome, chronic pain, chronic spinal pain, chronic opioid therapy, obesity, smoking, cardiovascular risk factors, pulmonary risk factors

Pain Physician 2016; 19:E569-E579 


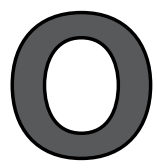
bstructive sleep apnea syndrome (OSAS) is a common sleep disorder with complete or partial airway obstruction, disrupted sleep, and excessive daytime sleepiness (1). Obstructive sleep apnea has been reported to be common and undiagnosed with significant health and health care consequences (2-5). Since its description in 1976 by Guilleminault et al (6), our understanding of sleep apnea syndrome has expanded with the publication of numerous epidemiologic studies and systematic reviews (1,2,7-21). In addition, multiple comorbidities related to cardiovascular sequelae with increase in morbidity and mortality, altered cognitive function with daytime sleepiness leading to motor vehicle crashes and occupational accidents, and description of multiple other potential complications have been established (1,2,7-21). Further, multiple risk factors have been described including obesity, smoking, alcohol consumption, and other factors (7,22-30). However, chronic pain and chronic opioid therapy, which have been characterized to constitute a large proportion of patients with OSAS (31-35), have not been widely discussed as risk factors (1,2,7-21). Chronic pain, obesity, smoking, and chronic opioid therapy are major health care issues and all conditions may present in a single patient in chronic pain management settings $(36,37)$.

Obesity, defined as body mass index (BMI) of 30 or higher, has been described in approximately 80 million Americans and is associated with an increased risk of serious medical conditions including heart disease, diabetes, cancer, stroke, hypertension, arthritis, high blood pressure, and more (38). In the United States, more than $30 \%$ of adults and $17 \%$ of children are considered obese and these rates have been climbing steadily since 1980 (38). Similarly, tobacco abuse remains the single largest preventable cause of death and disease in the United States with almost half a million deaths each year with more than 41,000 of these deaths resulting from exposure to secondhand smoke (39). The costs of obesity and smoking have been skyrocketing, ranging from $\$ 147$ billion to nearly $\$ 210$ billion per year for obesity: $\$ 14$ billion in direct medical costs attributed to $21 \%$ of the medical costs to obesity (38). Similarly, smoking related illness in the United States costs more than $\$ 300$ billion a year, including nearly $\$ 170$ billion in direct medical care for adults and $\$ 160$ billion due to a loss in productivity $(39,40)$. The prevalence of chronic pain and its associated disability (41-49) and chronic opioid therapy (50-65) with its adverse consequences continues to escalate in the United States and across the globe. In addition to the escalating prevalence of chronic pain, the $400 \%$ increase in opioid consumption and the associated consequences including opioidrelated deaths has been a major focus of policy makers in the United States (66). Chronic pain patients also present with multiple psychological disorders and often undergo drug therapy with multiple psychoactive substances including benzodiazepines, leading to a higher risk of many adverse consequences including OSAS $(50,67-75)$.

The prevalence estimates have been highly variable for OSAS (1,76-89). Early population-based studies suggested the prevalence of OSAS as $4 \%$ in men and $2 \%$ in women (82) with the rate of prevalence ranging from $0.7 \%$ to $3.3 \%(82-86)$. However, it has been claimed obstructive sleep apnea is often asymptomatic and the prevalence of patients with OSAS who do not present with clinical syndromes might be as high as $20 \%$ to $30 \%$ in the middle-aged population $(1,88)$. In fact, a review on the epidemiology of sleep apnea by Franklin and Lindberg (76) indicated daytime sleepiness occurred in $6 \%$ (range $3 \%$ to $18 \%$ ) of men and $4 \%(1 \%$ to $17 \%)$ of women. They also showed that the prevalence of daytime sleepiness increased with time and OSAS was reported in $37 \%$ of men and $50 \%$ of women in studies from 2008 and 2013, respectively. In addition, obstructive sleep apnea was diagnosed in $35 \%$ to $57 \%$ of patients managed in long-term pain clinics (33). Farney et al (89), in a population of young, non-obese, long-term opioid users, found obstructive sleep apnea in $63 \%$ of patients on opioids, even though moderate obstructive sleep apnea was seen in $16 \%$ and severe sleep apnea was seen in $17 \%$ of the patients. Similar to opioid therapy, obesity is believed to predispose patients to obstructive sleep apnea because of mass loading in the upper airway. Sharkey et al (90) showed that OSAS is more common than central sleep apnea in methadone maintenance patients. Young et al (91) estimated that $58 \%$ of moderate to severe cases of obstructive sleep apnea are due to a BMI above 25. Smoking and related complications with chronic obstructive pulmonary disorders have been linked to high prevalence of obstructive sleep apnea (76) due to possible airway inflammation and sleep instability from overnight nicotine withdrawal. The prevalence of smoking in patients with obstructive sleep apnea was found to be $35 \%$, whereas it was only $18 \%$ in patients without obstructive sleep apnea. Thus, considering that many patients in chronic pain settings are middle aged, take opioids and benzodiazepines, and are obese and 
smoke, it is logical that a large proportion of chronic pain patients suffer with OSAS. However, in clinical practice, we have not observed such high occurrence of symptomatic OSAS; consequently, we have undertaken this retrospective assessment to facilitate a prospective evaluation to assess symptomatic OSAS in chronic spinal pain patients.

\section{Methods}

This retrospective assessment, based on the Strengthening the Reporting of Observational Studies in Epidemiology (STROBE) guidelines (92), was conducted in the United States in a private interventional pain management practice, a specialty referral center. Approval from the Institutional Review Board (IRB) was not required since only data collection without identification of patients was involved. The study was conducted with internal resources of the practice without any external funding.

All new patients were given an explanation of the initial evaluation and the information collection process. Informed consent was obtained from all patients prior to assessment. Appropriate precautions were taken to protect the privacy of all patients and full confidentially was maintained.

The inclusion criteria were that patients be over 18 years of age and had been referred to a pain management center with spinal pain that lasted for at least one year. In addition, patients must be willing to undergo the appropriate assessment and must be able to provide voluntary written informed consent for the evaluation. Exclusion criteria included an inability to understand the process, pain of less than a one-year duration, nonspinal pain, and patients unwilling to participate in the evaluation process.

As standard protocol dictates, a complete medical history was obtained from patients, which included 15 systems: skin, hematologic/lymphatic, head/face, eyes, ear/nose/mouth, chest/breast, respiratory, cardiac/ peripheral vascular, hepatic - biliary/gastrointestinal/ abdominal, urinary, genital/reproductive, endocrine, musculoskeletal, neurological/psychiatric. As part of the review of the respiratory system, all patients were asked if they suffered from multiple pulmonary ailments including OSAS or symptoms related to OSAS. Diagnosis of OSAS was confirmed by an accredited sleep lab.

\section{Demographics of Sample}

The sample in this study included 4,036 patients who were refereed to a single private interventional pain management center. All patients underwent evaluation by one of 2 physicians from January 2010 to December 2014. All patients aged 18 years and older were evaluated with a history, review of medical history, physical examination, psychological evaluation, review of records, urine drug testing, and collected demographics, weight, and height. These evaluations are a normal component of the comprehensive evaluation provided to patients at this clinic. No incentive, financial or otherwise, was provided to patients who were included in this study.

\section{Statistical Methods}

Statistical analysis was performed with IBM SPSS 22.0 for Windows packaged software. Univariate analysis and multivariate binary logistic regression analysis were performed to calculate the odds ratio and 95\% confidence intervals for OSAS. Results were considered statistically significant if the $P$ value was less than 0.05 . Pack yearsis calculated by number of packs of cigarettes smoked per day multiplied by years of smoking.

\section{Results}

Patient Demographics and Association of Obstructive Sleep Apnea Syndrome

The mean age was $48.8+13.6$ years; mean weight was $195.5+54.5$ lbs.; mean height was $66.9+4.1$ inches; the mean BMI was $30.5+7.9$ (Table 1). Of all the patients included in this study, approximately $57 \%$ ( $n=2,314)$ were females and approximately $43 \%$ ( $n=$ 1,722) were male.

The prevalence of symptomatic and OSAS was $13.8 \%$ with no significant difference between the 2 physicians ( $14.7 \%$ vs $12.9 \%$ ). As shown in Table 1 , the prevalence of OSAS was significantly higher in males (15.1\%) compared to females $(12.8 \%)$. The prevalence of OSAS was higher in patients over 45 years of age $(16.3 \%)$ and the prevalence of OSAS was lower in patients aged $18-24.9$ years $(2.5 \%)$. The prevalence of OSAS was greater in African American patients (16.2\%) compared to white patients (13.4\%).

OSAS is positively associated with number of pain problems(back or neck only or combined back and neck pain) and BMI. The prevalence of OSAS was higher in patients with combined back and neck symptoms $(16.3 \%)$ rather than patients presenting with either thoracic pain only, neck pain only, or back pain only with a prevalence of $8.2 \%$ to $11.0 \%$.

There was significant association between prevalence of OSAS and BMI. While the prevalence was shown 
Table 1. Association between demographic characteristics and obstructive sleep apnea syndrome.

\begin{tabular}{|c|c|c|c|c|c|c|c|}
\hline & Number & $\begin{array}{c}\text { Obstructive sleep } \\
\text { apnea syndrome } \\
\text { (OSAS) absent }\end{array}$ & $\begin{array}{l}\text { Obstructive sleep } \\
\text { apnea syndrome } \\
\text { (OSAS) present }\end{array}$ & $\begin{array}{l}\text { Prevalence of } \\
\text { obstructive } \\
\text { sleep apnea } \\
\text { syndrome } \\
\text { (OSAS) }\end{array}$ & $\begin{array}{c}\text { Odds of } \\
\text { obstructive } \\
\text { sleep apnea } \\
\text { syndrome } \\
\text { (OSAS) }\end{array}$ & $\begin{array}{c}\text { Odds ratio } \\
\text { compare } \\
\text { to baseline } \\
(0)\end{array}$ & $\begin{array}{c}P \\
\text { value }\end{array}$ \\
\hline \multicolumn{8}{|l|}{ Gender } \\
\hline Female & 2,314 & 2,018 & 296 & $12.8 \%$ & 0.147 & 1.000 & \multirow{2}{*}{0.038} \\
\hline Male & 1,722 & 1,462 & 260 & $15.1 \%$ & 0.178 & 1.212 & \\
\hline \multicolumn{8}{|l|}{ Age (years) } \\
\hline $18-24.9$ & 120 & 117 & 3 & $2.5 \%$ & 0.026 & 1.000 & \multirow{3}{*}{0.000} \\
\hline $25-44.9$ & 1,517 & 1,354 & 163 & $10.7 \%$ & 0.120 & 4.709 & \\
\hline$\geq 45$ & 2,399 & 2,009 & 390 & $16.3 \%$ & 0.194 & 7.594 & \\
\hline \multicolumn{8}{|l|}{ Race } \\
\hline White & 3,652 & 3,161 & 491 & $13.4 \%$ & 0.155 & 1.000 & \multirow{3}{*}{0.075} \\
\hline African American & 246 & 190 & 56 & $16.2 \%$ & 0.295 & 2.168 & \\
\hline Hispanic and Asian & 38 & 29 & 9 & $23.7 \%$ & 0.310 & 2.282 & \\
\hline \multicolumn{8}{|l|}{ Chronic Pain } \\
\hline Thoracic pain only & 184 & 169 & 15 & $8.2 \%$ & 0.089 & 1.000 & \multirow{4}{*}{0.000} \\
\hline Neck pain only & 169 & 153 & 16 & $9.5 \%$ & 0.105 & 1.178 & \\
\hline Back pain only & 1,452 & 1,295 & 157 & $11.0 \%$ & 0.121 & 1.366 & \\
\hline Back \& neck & 2,258 & 1,890 & 368 & $16.3 \%$ & 0.195 & 2.194 & \\
\hline \multicolumn{8}{|l|}{ BMI } \\
\hline Normal $(<25)$ & 1,042 & 983 & 59 & $5.7 \%$ & 0.060 & 1.00 & \multirow{5}{*}{0.00} \\
\hline Overweight $(25-30)$ & 1,180 & 1,072 & 108 & $9.2 \%$ & 0.101 & 1.678 & \\
\hline Obese $(>30-35)$ & 839 & 707 & 132 & $15.7 \%$ & 0.187 & 3.111 & \\
\hline Severely obese $(>35-40)$ & 477 & 380 & 97 & $20.3 \%$ & 0.255 & 4.253 & \\
\hline Morbid obese $(\geq 40)$ & 487 & 329 & 158 & $32.4 \%$ & 0.480 & 8.001 & \\
\hline
\end{tabular}

Baseline is where coded value is 0 .

to be $5.7 \%$ in patients with normal weight and BMI, it gradually increased to $9.2 \%$ in those who were overweight, $15.7 \%$ in those who were obese with a BMI of 30 to $35,20.3 \%$ in those who were severely obese with a $\mathrm{BMI}$ of 35 to 40 , and $32.4 \%$ in morbidly obese patients.

\section{Correlation with Chronic Opioid and Benzodiazepine Treatment}

Table 2 shows the correlation of prevalence of OSAS with chronic opioid therapy alone or a combination of opioid therapy and benzodiazepine therapy. The prevalence of OSAS was $10.5 \%$ in patients with chronic pain with no opioid or benzodiazepine therapy compared to $13.9 \%$ in patients receiving long-term opioids. In contrast, the prevalence of OSAS was $13.8 \%$ in patients receiving a combination of opioids and benzodiazepines, which is similar the prevalence in patients receiving opioids alone.

\section{Correlation with Smoking and Respiratory Disorders}

As shown in Table 3, the prevalence of OSAS was $15.7 \%$ in nonsmokers and $13.3 \%$ in smokers. However, the mean age was $51.6 \pm 15.7$ in nonsmokers compared to the mean age of smokers of $48.1+12.92$, which may partly explain the higher prevalence in nonsmokers. Further, the ratio of male and female was also significantly different with a higher proportion of males. However, the frequency and level of smoking showed significant correlation with those smoking greater than 40 pack years with a significantly higher prevalence of OSAS at $16.3 \%$ compared to those smoking less than 40 pack years, where pack years is calculated by multiplying the number of packs of cigarettes smoked per day 
Table 2. Correlation of prevalence of obstructive sleep apnea syndrome with chronic opioid and/or benzodiazepine therapy.

\begin{tabular}{|l|c|c|c||}
\hline & $\begin{array}{c}\text { Obstructive sleep apnea } \\
\text { syndrome (OSAS) absent }\end{array}$ & $\begin{array}{c}\text { Obstructive sleep apnea } \\
\text { syndrome (OSAS) present }\end{array}$ & Total \\
\hline No opioid or benzodiazepine therapy & 154 & $18(10.5 \%)$ & 172 \\
\hline Chronic opioid therapy & 2,308 & $374(13.9 \%)$ & 2682 \\
\hline Chronic benzodiazepine therapy & 15 & $4(21.1 \%)$ & 19 \\
\hline Combined opioid and benzodiazepine & 1,003 & $160(13.8 \%)$ & 1163 \\
\hline Total & 3,480 & $556(13.8 \%)$ & 4,036 \\
\hline
\end{tabular}

$P<0.475$

Table 3. Correlation of smoking and Obstructive sleep apnea syndrome.

\begin{tabular}{||l|c|c|c|c|c|c||}
\hline & Number & Mean Age & $\begin{array}{c}\text { Prevalence of } \\
\text { obstructive sleep } \\
\text { apnea syndrome } \\
\text { (OSAS) }\end{array}$ & $\begin{array}{c}\text { Odds of obstructive } \\
\text { sleep apnea } \\
\text { syndrome (OSAS) }\end{array}$ & $\begin{array}{c}\text { Odds ratio } \\
\text { compared to } \\
\text { baseline (0) }\end{array}$ & $\begin{array}{c}\text { P value } \\
\text { (0) }\end{array}$ \\
\hline Smoking & 840 & $51.6 \pm 15.7$ & $15.7 \%(132)$ & 0.1864 & 1.0000 & 0.072 \\
\hline No & 3,196 & $48.1^{*} \pm 12.92$ & $13.3 \%(424)$ & 0.1530 & 0.8204 & 1.0000 \\
\hline Yes & & & & 0.115789 & 0.9811 & 0.001 \\
\hline Pack Years \# & 1,060 & $40.6 \pm 11.5$ & $10.4 \%(110)$ & 0.1136 & 1.6831 \\
\hline$<20$ pack years
\end{tabular}

\# For 825 patients, pack years information was not available.

Pack years $=$ packs of cigarettes smoked per day $\mathrm{x}$ years of smoking

by the number of years the person has smoked.

OSAS is positively associated with several respiratory problems, including nasal discharge, chronic sinus infections and allergies, bronchial asthma, emphysema, and chronic obstructive pulmonary disease (COPD) (Table 4). The prevalence of OSAS was higher in patients with sinus discharge, chronic sinus problems, bronchial asthma, emphysema, and finally, COPD. However, there was no significant difference in prevalence of OSAS between patients with or without chronic bronchitis as shown in Table 4.

As shown in Table 5, the prevalence of OSAS was significantly higher in patients with hypertension, hyperlipidemia, coronary artery disease (CAD), congestive heart failure or stroke, and those receiving antiplatelet therapy.

\section{Assessment of Significant Correlates}

Significant correlation of multiple factors with risk and comorbidity are illustrated in Table 6.

Based on the binary logistic regression analysis, the factors with a significant level of association with OSAS were age (Exp [B]: 1.009), BMI (Exp [B]: 1.088), gender (Exp [B]: 0.626), sinus or nasal discharge (Exp [B]: 1.571), chronic sinus infections and allergies (Exp [B]: 1.832), COPD (Exp [B]: 1.441), hyperlipidemia (Exp [B]: 1.617), ASCVD/CAD (Exp [B]: 1.811), and history of congestive heart failure or stroke (Exp [B]: 1.988). However there was not a significant association with OSAS and smoking and chronic bronchitis.

\section{Discussion}

The results of this assessment of over 4,000 patients in a chronic pain management center with spinal pain of longer than one year with the majority of them on chronic opioid therapy have shown the prevalence of symptomatic OSAS as $13.8 \%$. The results also showed a higher prevalence in males compared to females (15.1\% versus $12.8 \%)$, higher prevalence in those aged 45 or over compared to those younger than 45 (16.3\% versus $10.7 \%$ or $2.5 \%$ ), higher prevalence in Hispanics and Asians compared to African-Americans and whites ( $23.7 \%$ versus $16.2 \%$ versus $13.4 \%$ ), higher prevalence in patients with combined back and neck pain than involvement of a single region (16.3\% versus $8.2 \%$ $11 \%$ ), and $32.4 \%$ in morbidly obese patients, $20.3 \%$ in severely obese patients, $15.7 \%$ in obese patients, $9.2 \%$ in those who were overweight, and $5.7 \%$ in those who 
Pain Physician: May/June 2016: 19:E569-E579

Table 4. Correlation of respiratory disorders and obstructive sleep apnea syndrome.

\begin{tabular}{|c|c|c|c|c|c|c|}
\hline & \multicolumn{2}{|c|}{ Number } & \multirow{3}{*}{$\begin{array}{c}\begin{array}{c}\text { Prevalence of } \\
\text { obstructive sleep apnea } \\
\text { syndrome (OSAS) }\end{array} \\
11.3 \%(311) \\
19.0 \%(245) \\
\end{array}$} & \multirow{3}{*}{$\begin{array}{c}\text { Odds of obstructive } \\
\text { sleep apnea } \\
\text { syndrome (OSAS) } \\
0.127616 \\
0.234899 \\
\end{array}$} & \multirow{3}{*}{\begin{tabular}{|c|}
$\begin{array}{c}\text { Odds ratio } \\
\text { compared to } \\
\text { baseline (0) }\end{array}$ \\
1.0000 \\
1.8407 \\
\end{tabular}} & \multirow{3}{*}{$\begin{array}{c}\boldsymbol{P} \text { value } \\
0.000\end{array}$} \\
\hline \multirow{2}{*}{ Sinus and nasal discharge } & No $(0)$ & 2,748 & & & & \\
\hline & Yes (1) & 1,288 & & & & \\
\hline \multirow{2}{*}{ Chronic sinus infections/allergies } & No $(0)$ & 3,252 & $11.8 \%(385)$ & 0.134287 & 1.0000 & \multirow{2}{*}{0.000} \\
\hline & Yes (1) & 784 & $21.8 \%(171)$ & 0.278956 & 2.0773 & \\
\hline \multirow{2}{*}{ Bronchial asthma } & No $(0)$ & 3,734 & $13.1 \%(491)$ & 0.151403 & 1.0000 & \multirow{2}{*}{0.000} \\
\hline & Yes (1) & 302 & $21.5 \%(65)$ & 0.274262 & 1.8115 & \\
\hline \multirow{2}{*}{ Chronic bronchitis } & No $(0)$ & 2,774 & $13.4 \%(371)$ & 0.15439 & 1.0000 & \multirow{2}{*}{0.147} \\
\hline & Yes (1) & 1,262 & $14.7 \%(185)$ & 0.171773 & 1.1126 & \\
\hline \multirow{2}{*}{ Emphysema } & No $(0)$ & 3,052 & $13.3 \%(405)$ & 0.153003 & 1.0000 & \multirow{2}{*}{0.057} \\
\hline & Yes (1) & 984 & $15.3 \%(151)$ & 0.181273 & 1.1848 & \\
\hline \multirow{2}{*}{$\begin{array}{l}\text { Chronic obstructive pulmonary } \\
\text { disease (COPD) }\end{array}$} & No $(0)$ & 3,234 & $11.9 \%(385)$ & 0.135135 & 1.0000 & \multirow{2}{*}{0.000} \\
\hline & Yes (1) & 802 & $21.3 \%(171)$ & 0.270998 & 2.0054 & \\
\hline
\end{tabular}

Table 5. Correlation of cardial related disorders and obstructive sleep apnea syndrome.

\begin{tabular}{|c|c|c|c|c|c|c|}
\hline & \multicolumn{2}{|c|}{ Number } & $\begin{array}{l}\text { Prevalence ofobstructive } \\
\text { sleep apnea syndrome }\end{array}$ & $\begin{array}{c}\text { Odds of obstructive } \\
\text { sleep apnea }\end{array}$ & $\begin{array}{c}\text { Odds ratio } \\
\text { compare to }\end{array}$ & $P$ value \\
\hline \multirow{2}{*}{ Hypertension } & No $(0)$ & 2,475 & $10.1 \%(249)$ & 0.11186 & 1.0000 & \multirow{2}{*}{0.000} \\
\hline & Yes (1) & 1,561 & $19.7 \%(307)$ & 0.244817 & 2.1886 & \\
\hline \multirow{2}{*}{ Hyperlipidemia } & No $(0)$ & 3,131 & $10.5 \%(328)$ & 1.0000 & $10.5 \%$ & \multirow{2}{*}{0.000} \\
\hline & Yes (1) & 905 & $25.2 \%(228)$ & 2.8780 & $25.2 \%$ & \\
\hline \multirow{2}{*}{$\begin{array}{l}\text { Atherosclerotic cardiovascular } \\
\text { disease /CAD }\end{array}$} & No $(0)$ & 3,524 & $11.5 \%(405)$ & 0.129849 & 1.0000 & \multirow{2}{*}{0.000} \\
\hline & Yes (1) & 512 & $29.5 \%(151)$ & 0.418283 & 3.2213 & \\
\hline \multirow{2}{*}{$\begin{array}{l}\text { H/o congestive heart } \\
\text { failure/stroke }\end{array}$} & No $(0)$ & 3,855 & $12.8 \%(492)$ & 0.146298 & 1.0000 & \multirow{2}{*}{0.000} \\
\hline & Yes (1) & 181 & $35.4 \%(64)$ & 0.547009 & 3.7390 & \\
\hline \multirow{2}{*}{ Anti-platelet therapy } & No $(0)$ & 3,438 & $11.5 \%(396)$ & 0.1302 & 1.0000 & \multirow{2}{*}{0.000} \\
\hline & Yes (1) & 598 & $26.8 \%(160)$ & 0.3653 & 2.8061 & \\
\hline
\end{tabular}

were normal weight. In addition, there was a significant correlation between pack-years and OSAS, even though the prevalence of OSAS was not higher in smokers compared to nonsmokers. There was a correlation between OSAS and patients with multiple respiratory problems including sinus and nasal discharge, chronic sinus infections or allergies, bronchial asthma, emphysema, and COPD. However, there were no significant differences noted in patients with chronic bronchitis. The results also showed a significant positive correlation with hypertension, hyperlipidemia, CAD, history of congestive failure or stroke, and antiplatelet therapy with a higher prevalence of OSAS. These findings are consistent with previous reports $(1,76-89,93-95)$ with in- creasing age, male gender, obesity, COPD, and chronic pain, as well as opioid therapy alone, or opioid therapy with benzodiazepines.

As discussed earlier, the prevalence of OSAS is highly variable $(1,76-89)$. Despite early studies suggesting the prevalence of OSAS ranges from $0.7 \%$ to $3.3 \%$ (82-86), the prevalence of asymptomatic OSAS might be as high as $20 \%$ to $30 \%(1,88)$. Franklin and Lindberg (76) showed that the prevalence increased with time, with prevalence reaching $37 \%$ in men and $50 \%$ in women, and the prevalence of obstructive sleep apnea defined at an apnea-hypopnea index of greater than 5 was a mean of $22 \%$ (range $9 \%$ to $37 \%$ ) in men and $17 \%$ (4\% to $50 \%)$ in women in 11 published epidemiologi- 
Table 6. Assessment of significant correlation among multiple risk factors and comorbidities with obstructive sleep apnea syndrome.

\begin{tabular}{|c|c|c|c|c|c|c|c|c|}
\hline & \multirow{2}{*}{$\mathbf{B}$} & \multirow{2}{*}{$\mathbf{S E}$} & \multirow{2}{*}{ Wald } & \multirow{2}{*}{ df } & \multirow{2}{*}{ Sig. } & \multirow{2}{*}{$\operatorname{Exp}(B)$} & \multicolumn{2}{|c|}{ 95\% CI for $\operatorname{Exp}($ B) } \\
\hline & & & & & & & Lower & Upper \\
\hline Age (Years) & .009 & .004 & 3.882 & 1 & 0.049 & 1.009 & 1.000 & 1.017 \\
\hline BMI & .085 & .006 & 190.184 & 1 & 0.000 & 1.088 & 1.075 & 1.101 \\
\hline Gender & -.469 & .104 & 20.385 & 1 & 0.000 & 0.626 & 0.510 & 0.767 \\
\hline Smoking & .096 & .125 & .590 & 1 & 0.442 & 1.101 & 0.861 & 1.408 \\
\hline Sinus or nasal discharge & .452 & .103 & 19.133 & 1 & 0.000 & 1.571 & 1.283 & 1.924 \\
\hline Infections or allergies & .606 & .115 & 27.747 & 1 & 0.000 & 1.832 & 1.463 & 2.295 \\
\hline Bronchial asthma & .115 & .172 & .446 & 1 & 0.504 & 1.122 & 0.801 & 1.572 \\
\hline Chronic bronchitis & -.047 & .119 & .158 & 1 & 0.691 & 0.954 & 0.755 & 1.205 \\
\hline \multicolumn{9}{|l|}{ Emphysema } \\
\hline COPD & .366 & .127 & 8.282 & 1 & 0.004 & 1.441 & 1.124 & 1.849 \\
\hline Hypertension & .060 & .109 & .303 & 1 & 0.582 & 1.062 & 0.858 & 1.315 \\
\hline Hyperlipidemia & .481 & .115 & 17.536 & 1 & 0.000 & 1.617 & 1.291 & 2.026 \\
\hline $\mathrm{CAD}$ & .594 & .145 & 16.781 & 1 & 0.000 & 1.811 & 1.363 & 2.406 \\
\hline $\begin{array}{l}\mathrm{H} / \mathrm{o} \text { congestive heart failure or } \\
\text { stroke }\end{array}$ & .687 & .188 & 13.349 & 1 & 0.000 & 1.988 & 1.375 & 2.875 \\
\hline Anti-platelet therapy & .237 & .143 & 2.775 & 1 & 0.096 & 1.268 & 0.959 & 1.677 \\
\hline Constant & -5.534 & .323 & 292.845 & 1 & 0.000 & 0.004 & & \\
\hline
\end{tabular}

B - the coefficient for the constant (also called the "intercept"), SE - Standard error around the coefficient for the constant, Wald - Wald chisquare test, $\operatorname{Exp}(\mathrm{B})$ - Exponentiation of the B coefficient, which is an odds ratio.

cal studies between 1993 and 2013. However, none of these studies have shown chronic pain or chronic opioid therapy as risk factors. Guilleminault et al (33) showed that the majority of patients were found to have sleep-disorder breathing, whereas, Farney et al (89) found obstructive sleep apnea in $63 \%$ of patients on opioids, with severe sleep apnea in $17 \%$ of the patients and moderate sleep apnea in $16 \%$ of the patients. In methadone users, obstructive sleep apnea was diagnosed in $35 \%$ of the patients (90), with another study contradicting these results without any significant increase in sleep apnea in another group of patients (96). Further, in fibromyalgia patients (97), obstructive sleep apnea was shown to have an incidence of 10-fold higher than in the normal population. In another study of patients with chronic neck or low back pain (81), high sleep deprivation was seen in $42 \%$ of the patients even though obstructive sleep apnea was not assessed. Further, studies in patients with headaches showed no significant differences with occurrence of sleep apnea syndrome (55). Our study shows a modest prevalence of sleep apnea in patients with chronic low back and neck pain with a higher prevalence in patients with pain in multiple regions, and a prevalence of $16.3 \%$ in patients with back and neck pain compared to $8.2 \%$ with tho- racic pain only, $9.5 \%$ with neck pain only, and $11 \%$ in those with back pain only.

In this study, we are unable to determine the differences between chronic pain patients with or without opioid therapy since an overwhelming majority of the patients were on chronic opioid therapy and a significant proportion were on chronic benzodiazepines and opioid combination therapy. In a small number of patients without opioid or benzodiazepine therapy (154 of 4,032 patients), the prevalence was shown to be $10.5 \%$ compared to those with chronic opioid therapy or combined opioid and benzodiazepine therapy at almost $14 \%$. Overall this study may not resolve the issue in relation to the association of chronic pain or chronic pain with chronic opioid therapy.

Epidemiologic studies report the prevalence of OSAS as almost 8 times greater in patients over 45 years compared to patients 18 - 24.9 years (1,76-89, 93-95). Age was a marginally significant predictor in the binary logistic regression analysis. The effect of age is of particular interest as some research suggests that the nature of sleep disorders is distinct depending on the age group, with middle and older age groups exhibiting a higher prevalence of central events and more severe cases of sleep apnea occurring in the young 
(95). Furthermore, sleep-related problems in older populations may be a natural part of the aging process without a serious increased risk of mortality or morbidity (98). Gender is also a risk factor for OSAS, with a higher prevalence in male patients compared to female patients. In addition, gender was a significant predictor in the regression model.

Higher levels of BMI were associated with a higher prevalence of OSAS and BMI was also a significant predictor in the regression model, in accordance with previous studies $(91,99)$. These findings are important in chronic pain management settings. A large proportion $(74 \%)$ of patients are either overweight or obese and the data from this study shows approximately a quarter of patients were either severely obese or morbidly obese. Further, prevalence of OSAS was $20.3 \%$ in severely obese patients and $32.4 \%$ in morbidly obese patients. Considering the significant impact of obesity and related medical costs, identification of sleep apnea syndrome and avoidance are crucial (38).

There is not a clear consensus on the effects of smoking on OSAS. Our results indicated that the prevalence of OSAS was greater in nonsmokers compared to smokers. In addition, smoking was not a significant predictor in the regression analysis $(21,40)$. Previous studies have reported an increased prevalence of OSAS in smokers $(16,89)$. However, patients who smoked greater than 40 pack years had a higher prevalence of OSAS compared to those who smoked less. It has been previously hypothesized that smoking increases the risk of OSAS through several mechanisms including airway inflammation and the effects of lowered blood nicotine levels on the stability of sleep.

In addition, multiple other factors showing higher prevalence included sinus or nasal discharge, chronic sinus infections or allergies, bronchial asthma, emphysema, COPD, hypertension, hyperlipidemia, CAD, history of congestive heart failure or stroke, and antiplatelet therapy. The literature on multiple factors in chronic pain is scant. These risk factors and subsequent comorbidities may influence treatment options. There are many advantages to this assessment, along with multiple limitations. The advantages include a large sample size, chronic spinal pain patients with at least one year of duration of pain, chronic opioid therapy, and associated multiple comorbidities. The limitations include the retrospective nature of the analysis with a potentially higher prevalence of symptomatic OSAS, and even significantly higher proportion of asymptomatic obstructive sleep apnea or syndrome and lack of evaluation of patients with potential OSAS.

Overall, our results show a significantly lower prevalence of OSAS in spinal pain patients and also in patients undergoing chronic opioid therapy. This may be due to inclusion of a heterogenous sample with a large number of patients with or without OSAS and with or without chronic opioid therapy. The previous estimations utilized either specific patients selected with suspected OSAS, or smaller sample sizes. Considering a major triad of chronic pain, chronic opioid therapy, and obesity, with numerous adverse consequences and escalating health costs, physicians must be cautious in administering chronic opioid therapy in patients suspected of OSAS. In those who are diagnosed with sleep apnea syndrome, if chronic opioid therapy is administered, the patients must be monitored cautiously for any sleep disturbances including those of OSAS and the nighttime doses of opioids must be avoided. The results of this study are also important in that they are applicable to clinical settings of pain management with chronic opioid therapy.

\section{Conclusion}

This retrospective assessment of over 4,000 patients showed the prevalence of sleep apnea syndrome in $13.8 \%$ of the patients suffering with chronic pain and also receiving chronic opioid therapy. Multiple risk factors and comorbidities including obesity, COPD, chronic sinus and nasal discharge, and multiple comorbidities including cardiovascular and related ailments have been identified. 


\section{References}

1. Mannarino MR, Di Filippo F, Pirro M. Obstructive sleep apnea syndrome. Eur ] Intern Med 2012; 23:586-593.

2. Pagel JF. The burden of obstructive sleep apnea and associated excessive sleepiness. J Fam Pract 2008; 57:S3-S8.

3. Tarasiuk A, Reuveni H. The economic impact of obstructive sleep apnea. Curr Opin Pulm Med 2013; 19:639-644.

4. Leger D, Bayon V, Laaban JP, Philip P. Impact of sleep apnea on economics. Sleep Med Rev 2012; 16:455-462.

5. Wittmann V, Rodenstein DO. Health care costs and the sleep apnea syndrome. Sleep Med Rev 2004; 8:269-279.

6. Guilleminault C, Tilkian A, Dement WC The sleep apnea syndromes. Annu Rev Med 1976; 27:465-484.

7. Young T, Peppard PE, Gottlieb DJ. Epidemiology of obstructive sleep apnea: A population health perspective. Am J Respir Crit Care Med 2002; 165:1217-1239.

8. Floras JS. Sleep apnea and cardiovascular risk. J Cardiol 2014; 63:3-8.

9. Badran M, Yassin BA, Fox N, Laher I, Ayas N. Epidemiology of sleep disturbances and cardiovascular consequences. Can J Cardiol 2015; 31:873-879.

10. Rodenstein D. Sleep apnea: Traffic and occupational accidents - individual risks, socioeconomic and legal implications. Respiration 2009; 78:241-248.

11. Myles H, Myles N, Antic NA, Adams $R$, Chandratilleke $M$, Liu D, Mercer J, Vakulin A, Vincent A, Wittert G, Galletly C. Obstructive sleep apnea and schizophrenia: A systematic review to inform clinical practice. Schizophr Res 2016; 170:222-225.

12. Marcus JA, Pothineni A, Marcus CZ, Bisognano JD. The role of obesity and obstructive sleep apnea in the pathogenesis and treatment of resistant hypertension. Curr Hypertens Rep 2014; 16:411.

13. Zhao LP, Kofidis T, Lim TW, Chan SP, Ong $\mathrm{TH}$, Tan $\mathrm{HC}$, Lee $\mathrm{CH}$. Sleep apnea is associated with new-onset atrial fibrillation after coronary artery bypass grafting. J Crit Care 2015; 30:1418.e1-e5.

14. Surani SR. Diabetes, sleep apnea, obesity and cardiovascular disease: Why not address them together? World ] Diabetes 2014; 5:381-384.

15. Miller JD, Aronis KN, Chrispin J, Patil KD, Marine JE, Martin SS, Blaha MJ, Blumenthal RS, Calkins H. Obesity, exercise, obstructive sleep apnea, and modifiable atherosclerotic cardiovascular dis- ease risk factors in atrial fibrillation. J Am Coll Cardiol 2015; 66:2899-2906.

16. Kim KS, Kim JH, Park SY, Won HR, Lee HJ, Yang HS, Kim HJ. Smoking induces oropharyngeal narrowing and increases the severity of obstructive sleep apnea syndrome. J Clin Sleep Med 2012; 8:367-374.

17. Kilpinen $R$, Saunamäki $T$, Jehkonen $M$. Information processing speed in obstructive sleep apnea syndrome: A review. Acta Neurol Scand 2014; 129:209-218.

18. Lurie A. Cardiovascular disorders associated with obstructive sleep apnea. Adv Cardiol 2011; 46:197-266.

19. Koren D, Chirinos JA, Katz LE, Mohler ER, Gallagher PR, Mitchell GF, Marcus $\mathrm{CL}$. Interrelationships between obesity, obstructive sleep apnea syndrome and cardiovascular risk in obese adolescents. Int J Obes (Lond) 2015; 39:1086-1093.

20. Teodorescu M, Barnet JH, Hagen EW, Palta M, Young TB, Peppard PE. Association between asthma and risk of developing obstructive sleep apnea. JAMA 2015; 313:156-164.

21. Greenberg-Dotan S, Reuveni H, Tal A Oksenberg A, Cohen A, Shaya FT, Tarasiuk A, Scharf SM. Increased prevalence of obstructive lung disease in patients with obstructive sleep apnea. Sleep Breath 2014; 18:69-75.

22. Al Lawati NM, Patel SR, Ayas NT. Epidemiology, risk factors, and consequences of obstructive sleep apnea and short sleep duration. Prog Cardiovasc Dis 2009; 51:285-293.

23. Shah N, Roux F. The relationship of obesity and obstructive sleep apnea. Clin Chest Med 2009; 30:455-465.

24. Varol Y, Anar C, Tuzel OE, Guclu SZ, Ucar ZZ. The impact of active and former smoking on the severity of obstructive sleep apnea. Sleep Breath 2015; 19:1279-1284.

25. Schwartz AR, Patil SP, Laffan AM, Polotsky V, Schneider H, Smith PL. Obesity and obstructive sleep apnea: Pathogenic mechanisms and therapeutic approaches. Proc Am Thorac Soc 2008; 5:185-192.

26. de Sousa AG, Cercato C, Mancini MC Halpern A. Obesity and obstructive sleep apnea-hypopnea syndrome. Obes $\operatorname{Rev}$ 2008; 9:340-354.

27. Lam JC, Sharma SK, Lam B. Obstructive sleep apnea: Definitions, epidemiology \& natural history. Indian J Med Res 2010; 131:165-170.
28. Pan Y, Wang W, Wang KS. Associations of alcohol consumption and chronic diseases with sleep apnea among US adults. Int J High Risk Behav Addict 2014; 3:e19088.

29. Ryan S, Crinion SJ, McNicholas WT. Obesity and sleep-disordered breathing - when two 'bad guys' meet. QJM 2014; 107:949-954.

30. Javaheri S, Malik A, Smith J, Chung E. Adaptive pressure support servoventilation: A novel treatment for sleep apnea associated with use of opioids. J Clin Sleep Med 2008; 4:305-310.

31. Lettieri CJ. The association of obstructive sleep apnea and chronic pain. Medscape, May 24, 2013.

www.medscape.com/viewarticle/804588

32. Rose AR, Catcheside PG, McEvoy RD, Paul D, Kapur D, Peak E, Vakulin A, Antic NA. Sleep disordered breathing and chronic respiratory failure in patients with chronic pain on long term opioid therapy. J Clin Sleep Med 2014; 10:847-852.

33. Guilleminault C, Cao M, Yue HJ, Chawla P. Obstructive sleep apnea and chronic opioid use. Lung 2010; 188:459-468.

34. Bennett RM, Jones J, Turk DC, Russell IJ, Matallana L. An internet survey of 2,596 people with fibromyalgia. BMC Musculoskelet Disord 2007; 8:27.

35. Cheatle MD, Webster LR. Opioid therapy and sleep disorders: Risks and mitigation strategies. Pain Med 2015; 16:S22-S26.

36. Manchikanti L, Pampati V, Fellows B, Beyer CD, Damron KS, Barnhill RC, Burks T. Characteristics of chronic low back pain in patients in an interventional pain management setting: A prospective evaluation. Pain Physician 2001; 4:131-142.

37. Manchikanti L, Cash KA, Malla Y, Pampati $\vee$, Fellows B. A prospective evaluation of psychotherapeutic and illicit drug use in patients presenting with chronic pain at the time of initial evaluation. Pain Physician 2013; 16:E1-E13.

38. Berrington de Gonzalez A, Hartge P, Cerhan JR, Flint AJ, Hannan L, Maclnnis RJ, Moore SC, Tobias GS, Anton-Culver $H$, Freeman LB, Beeson WL, Clipp SL, English DR, Folsom AR, Freedman DM, Giles G, Hakansson N, Henderson KD, Hoffman-Bolton J, Hoppin JA, Koenig $K L$, Lee IM, Linet MS, Park Y, Pocobelli G, Schatzkin A, Sesso HD, Weiderpass E, Willcox BJ, Wolk A, Zeleniuch-Jacquotte 
A, Willett WC, Thun MJ. Body-mass index and mortality among 1.46 million white adults. $N$ Engl J Med 2010; 363:2211-2219.

39. U.S. Department of Health and Human Services. The Health Consequences of Smoking-50 Years of Progress: A Report of the Surgeon General, 2014. Atlanta: U.S. Department of Health and Human Services, Centers for Disease Control and Prevention, National Center for Chronic Disease Prevention and Health Promotion, Office on Smoking and Health, 2014.

www.surgeongeneral.gov/library/ reports/50-years-of-progress/

40. Xu X, Bishop EE, Kennedy SM, Simpson SA, Pechacek TF. Annual healthcare spending attributable to cigarette smoking: An update. Am J Prev Med 2015; 48:326-333.

41. US Burden of Disease Collaborators. The state of US health, 1999-2010: Burden of diseases, injuries, and risk factors. JAMA 2013; 310:591-608.

42. Gaskin DJ, Richard P. The economic costs of pain in the United States. J Pain 2012; 13:715-724.

43. Martin BI, Deyo RA, Mirza SK, Turner JA, Comstock BA, Hollingworth W, Sullivan SD. Expenditures and health status among adults with back and neck problems. JAMA 2008; 299:656-664. Erratum in: JAMA 2008; 299:2630.

44. Manchikanti L, Singh V, Falco FJE, Benyamin RM, Hirsch JA. Epidemiology of low back pain in adults. Neuromodulation 2014; 17:3-10.

45. Hoy D, Brooks P, Blyth F, Buchbinder R. The epidemiology of low back pain. Best Pract Res Clin Rheumatol 2010; 24:769-781.

46. Martin BI, Turner JA, Mirza SK, Lee MJ, Comstock BA, Deyo RA. Trends in health care expenditures, utilization, and health status among US adults with spine problems, 1997-2006. Spine (Phila $\mathrm{Pa}$ 1976) 2009; 34:2077-2084.

47. Freburger JK, Holmes GM, Agans RP, Jackman AM, Darter JD, Wallace AS, Castel LD, Kalsbeek WD, Carey TS. The rising prevalence of chronic low back pain. Arch Intern Med 2009; 169:251-258.

48. Institute of Medicine (IOM). Relieving Pain in America: A Blueprint for Transforming Prevention, Care, Education, and Research. The National Academies Press, Washington, DC, June 29, 2011. www.iom.edu/ /media/Files/Re-
port\%20Files/2011/Relieving-Pain-inAmerica-A-Blueprint-for-TransformingPrevention-Care-Education-Research/ Pain\%2oResearch\%202011\%20Report\%2oBrief.pdf

49. Social Security Administration. Annual Statistical Report on the Social Security Disability Insurance Program, 2011 Baltimore, MD, Office of Research Evaluation and Statistics, 2011.

www.ssa.gov/policy/docs/statcomps/di_ asr/2011/di_asr11.pdf

50. Rudd RA, Aleshire N, Zibbell JE, Gladden RM. Increases in drug and opioid overdose deaths - United States, 20002014. MMWR Morb Mortal Wkly Rep 2015; 64:1-5.

51. Dart RC, Surratt HL, Cicero TJ, Parrino MW, Severtson G, Bucher-Bartelson B, Green JL. Trends in opioid analgesic abuse and mortality in the United States. N Engl ] Med 2015; 372:241-248.

52. Atluri S, Sudarshan G, Manchikanti L. Assessment of the trends in medical use and misuse of opioid analgesics from 2004 to 2011. Pain Physician 2014; 17:E119-E128.

53. Deyo RA, Von Korff M, Duhrkoop D. Opioids for low back pain. BM] 2015; 350:g6380.

54. Kolodny A, Courtwright DT, Hwang CS, Kreiner P, Eadie JL, Clark TW, Alexander GC. The prescription opioid and heroin crisis: A public health approach to an epidemic of addiction. Annu Rev Public Health 2015; 36:559-574.

55. Russell MB, Kristiansen HA, Kvaerner $\mathrm{KJ}$. Headache in sleep apnea syndrome: Epidemiology and pathophysiology. Cephalalgia 2014; 34:752-755.

56. Cicero TJ, Ellis MS, Harney J. Shifting patterns of prescription opioid and heroin abuse in the United States. N Engl J Med 2015; 373:1789-1790.

57. Walker JM, Farney RJ. Are opioids associated with sleep apnea? A review of the evidence. Curr Pain Headache Rep 2009; 13:120-126.

58. Jones CM, Lurie P, Woodcock J. Addressing prescription opioid overdose: Data support a comprehensive policy approach. JAMA 2014; 312:1733-1734.

59. Wilder CM, Miller SC, Tiffany E, Winhusen T, Winstanley EL, Stein MD. Risk factors for opioid overdose and awareness of overdose risk among veterans prescribed chronic opioids for addiction or pain.] Addict Dis 2015 [Epub ahead of print]. 6o. Han B, Compton WM, Jones CM, Cai R. Nonmedical prescription opioid use and use disorders among adults aged 18 through 64 years in the United States, 2003-2013. JAMA 2015; 314:1468-1478.

61. Werber A, Marschall U, L'hoest H, Hauser W, Moradi B, Chiltenwolf MS. Opioid therapy in the treatment of chronic pain conditions in Germany. Pain Physician 2015; 18:E323-E331.

62. Fischer B, Jones W, Murphy Y, lalomiteanu A, Rehm J. Recent developments in prescription opioid-related dispensing and harm indicators in Ontario, Canada. Pain Physician 2015; 18:E659-E662.

63. Mehendale AW, Goldman MP, Mehendale RP. Opioid overuse pain syndrome (OOPS): The story of opioids, prometheus unbound. J Opioid Manag 2013; 9:421-438.

64. Lev R, Petro S, Lee A, Lee O, Lucas J, Castillo EM, Egnatios J, Vilke GM. Methadone related deaths compared to all prescription related deaths. Forensic Sci Int 2015; 257:347-352.

65. Manchikanti L, Atluri S, Hansen $\mathrm{H}, \mathrm{Be}-$ nyamin RM, Falco FJE, Helm II S, Kaye $A D$, Hirsch JA. Opioids in chronic noncancer pain: Have we reached a boiling point yet? Pain Physician 2014; 17:E1-E10.

66. Centers for Disease Control and Prevention (CDC). CDC's Top Ten: 5 Health Achievements in 2013 and 5 Health Threats in 2014. December 17, 2013.

http://blogs.cdc.gov/cdcworksforyou 24-7/2013/12/cdc\%E2\%80\%99s-topten-5-health-achievements-in-2013and-5-health-threats-in-2014/

67. Manchikanti L, Fellows B, Singh V. Understanding psychological aspects of chronic pain in interventional pain management. Pain Physician 2002; 5:57-82.

68. Mieczkowski BP, Oduguwa A, Kowatch RA, Splaingard M. Risk factors for sleep apnea in children with bipolar disorder. J Affect Disord 2014; 167:20-24.

69. Jordan KD, Okifuji A. Anxiety disorders: Differential diagnosis and their relationship to chronic pain. J Pain Palliat Care Pharmacother 2011; 25:231-245.

70. Manchikanti L, Pampati V, Beyer CD, Damron KS. Do number of pain conditions influence emotional status? Pain Physician 2002; 5:200-205.

71. Manchikanti L, Pampati V, Damron KS, Beyer CD, Barnhill RC. Evaluation of psychological status in chronic low back pain: Comparison with general population. Pain Physician 2002; 5:149-155. 
72. Bener A, Verjee M, Dafeeah EE, Falah O, Al-Juhaishi T, Schlogl J, Sedeeq A, Khan S. Psychological factors: Anxiety, depression, and somatization symptoms in low back pain patients. J Pain Res 2013; 6:95-101.

73. Manchikanti L, Fellows B, Pampati V, Damron KS, Beyer CD, Barnhill RC. Comparison of psychological status of chronic pain patients with general population. Pain Physician 2002; 5:40-48.

74. Han C, Pae CU. Pain and depression: A neurobiological perspective of their relationship. Psychiatry Investig 2015; 12:1-8.

75. Manchikanti L, Giordano J, Boswell MV Fellows B, Manchukonda R, Pampati $V$. Psychological factors as predictors of opioid abuse and illicit drug use in chronic pain patients. J Opioid Manag 2007; 3:89-100.

76. Franklin KA, Lindberg E. Obstructive sleep apnea is a common disorder in the population - a review on the epidemiology of sleep apnea. J Thorac Dis 2015; 7:1311-1322.

77. Garvey JF, Pengo MF, Drakatos P, Kent BD. Epidemiological aspects of obstructive sleep apnea. J Thorac Dis 2015. 7:920-929.

78. Lee W, Nagubadi S, Kryger $\mathrm{MH}$, Mokhlesi B. Epidemiology of obstructive sleep apnea: A population-based perspective. Expert Rev Respir Med 2008; 2:349-364.

79. Kimoff RJ. When to suspect sleep apnea and what to do about it. Can ] Cardiol 2015; 31:945-948.

8o. Maspero C, Giannini L, Galbiati G, Rosso $\mathrm{G}$, Farronato $\mathrm{G}$. Obstructive sleep apnea syndrome: A literature review. Minerva Stomatol 2015; 64:97-109.

81. Artner J, Cakir B, Spiekermann JA, Kurz $S$, Leucht F, Reichel H, Lattig F. Preva- lence of sleep deprivation in patients with chronic neck and back pain: A retrospective evaluation of 1016 patients. J Pain Res 2013; 6:1-6.

82. Strollo Jr PJ, Rogers RM. Obstructive sleep apnea. N Engl J Med 1996; 334:99-104.

83. Lavie P. Incidence of sleep apnea in a presumably healthy working population: A significant relationship with excessive daytime sleepiness. Sleep 1983; 6:312-318.

84. Gislason $T$, Almqvist $M$, Eriksson $G$, Taube A, Boman G. Prevalence of sleep apnea syndrome among Swedish men-an epidemiological study. J Clin Epidemiol 1988; 41:571-576.

85. Cirignotta $F$, D'Alessandro R, Partinen M, Zucconi M, Cristina E, Gerardi R, Cacciatore FM, Lugaresi E. Prevalence of every night snoring and obstructive sleep apneas among 30-69-year-old men in Bologna, Italy. Acta Neurol Scand 1989; 79:366-372.

86. Schmidt-Nowara JR, Jennum P. Epidemiology of sleep apnea. In: Guilleminault C, Partinen M (eds). Obstructive Sleep Apnea Syndrome-Clinical Research and Treatment. Raven Press, New York, 1990, pp 1-8.

87. Bixler EO, Vgontzas AN, Ten Have T, Tyson $K$, Kales A. Effects of age on sleep apnea in men: I. Prevalence and severity. Am J Respir Crit Care Med 1998; 157:144-148.

88. Young T, Evans L, Finn L, Palta M. Estimation of the clinically diagnosed proportion of sleep apnea syndrome in middle-aged men and women. Sleep 1997; 20:705-706.

89. Farney RJ, Walker JM, Boyle KM, Cloward TV, Shilling KC. Adaptive servoventilation (ASV) in patients with sleep disordered breathing associated with chronic opioid medications for non-malignant pain. J Clin Sleep Med 2008; 4:311-319.

90. Sharkey KM, Kurth ME, Anderson BJ, Corso RP, Millman RP, Stein MD. Obstructive sleep apnea is more common than central sleep apnea in methadone maintenance patients with subjective sleep complaints. Drug Alcohol Depend 2010; 108:77-83.

91. Young T, Peppard PE, Taheri S. Excess weight and sleep disordered breathing. J Appl Physiol (1985) 2005; 99:1592-1599.

92. Vandenbroucke JP, Von Elm E, Altman DG, Gøtzsche PC, Mulrow CD, Pocock S), Poole C, Schlesselman JJ, Egger M; Iniciativa STROBE. Strengthening the reporting of observational studies in epidemiology (STROBE): Explanation and elaboration. Gac Sanit 2009; 23:158.

93. Young T, Skatrud J, Peppard PE. Risk factors for obstructive sleep apnea in adults. JAMA 2004; 291:2013-2016.

94. He J, Kryger MH, Zorick FJ, Conway W, Roth T. Mortality and apnea index in obstructive sleep apnea. Experience in 385 male patients. Chest 1988; 94:9-14.

95. Vgontzas AN, Tan TL, Bixler EO, Martin LF, Shubert D, Kales A. Sleep apnea and sleep disruption in obese patients. Arch Intern Med 1994; 154:1705-1711.

96. Webster LR, Choi Y, Desai H, Webster L, Grant BJ. Sleep-disordered breathing and chronic opioid therapy. Pain Med 2008; 9:425-432.

97. Moldofsky H, Scarisbrick P. Induction of neurasthenic musculoskeletal pain syndrome by selective sleep stage deprivation. Psychosom Med 1976; 38:35-44.

98. Malhotra A, White DP. Obstructive sleep apnea. Lancet 2002; 360:237-245.

99. Eckert DJ, Malhotra A, Jordan AS. Mechanisms of apnea. Prog Cardiovasc Dis 2009; 51:313-323. 
